\title{
Granger Causality and Equilibrium Business Cycle Theory
}

Yi Wen

\begin{abstract}
Postwar U.S. data show that consumption growth "Granger-causes" output and investment growth, which is puzzling if technology is the driving force of the business cycle. The author asks whether general equilibrium models with information frictions and non-technology shocks can rationalize the observed causal relationships. His conclusion is they cannot. (JEL E13, E32)
\end{abstract}

Federal Reserve Bank of St. Louis Review, May/June 2007, 89(3), pp. 195-205.

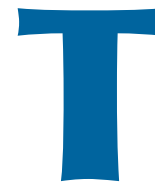

here is a "causal" relationship among consumption, output, and investment. Postwar U.S. data show that consumption growth "Granger-causes" gross domestic product (GDP) growth but not vice versa and that GDP growth in turn Grangercauses business investment growth but not vice versa. ${ }^{1}$ This unidirectional causal chain suggests that consumption contains better information about the source of shocks hitting the economy than does output, and output in turn contains better information about such shocks than does investment.

This causal relationship cannot be explained by standard real business cycle (RBC) models. For example, under technology shocks, output contains the best information possible for the source of shocks; hence, it will not appear to be "Granger-caused" by consumption once the history of output is taken into account. To rationalize the causal relationship found in the U.S. data, it seems natural to consider demand shocks and to add a richer information structure into standard models such that demand shocks can affect consumption before affecting output and investment. ${ }^{2}$

1 The concept of causality is defined according to Granger (1969).
I investigate whether existing equilibrium business cycle models driven by demand shocks (in particular, government spending shocks) can rationalize the observed causal relationship when the following information structure is embedded: (i) Employment and output cannot respond to demand shocks immediately; they can do so only with a lag behind consumption. And (ii) investment cannot respond to demand shocks immediately; it can do so only with a lag behind output. ${ }^{3}$

Under these ad hoc assumptions, I first show that standard general equilibrium business cycle models do predict the existence of a causal chain from consumption to output and investment, but with the wrong sign. Namely, consumption growth negatively causes output growth, and output

2 Hall (1978) first points out that consumption appears to be exogenous with respect to output and investment. More recently, Cochrane (1994) argues that the predictive power of consumption on output indicates that consumption shocks are important for the business cycle.

3 The rationale could be time-to-build or adjustment costs in employment and investment. Notice that preference shocks do not resolve the problem because under preference shocks consumption is not able to respond at the impact period when neither output nor investment can respond to the shocks. Consequently, consumption would contain the same information as output and would fail to Granger-cause output.

Yi Wen is a senior economist at the Federal Reserve Bank of St. Louis. The author thanks Mike Dueker, Nubo Kiyotaki, Mike Pakko, Karl Shell, Neil Wallace, and the seminar participants at the Cornell/Penn State Macro Conference (2002) for comments. Luke Shimek provided research assistance.

(c) 2007, The Federal Reserve Bank of St. Louis. Articles may be reprinted, reproduced, published, distributed, displayed, and transmitted in their entirety if copyright notice, author name(s), and full citation are included. Abstracts, synopses, and other derivative works may be made only with prior written permission of the Federal Reserve Bank of St. Louis. 
growth in turn negatively causes investment growth. ${ }^{4}$ In the U.S. data, however, these causal relationships are strictly positive. The negative causal chain emerges from standard models because of the crowding-out effect among components of aggregate demand in general equilibrium.

I then choose to mitigate the crowding-out problem by allowing for variable capacity utilization and production externalities in standard models, following Baxter and King (1990), Benhabib and Farmer (1994), Burnside and Eichenbaum (1996), Wen (1998), and Benhabib and Wen (2004). Variable capacity utilization and mild production externalities mitigate the crowding-out problem by creating short-run increasing returns to labor, which permit the expansion of output to meet aggregate demand with little increase in marginal costs in the short run. These modifications, however, bring about only limited success. The model now predicts that output growth positively causes investment growth, but it fails to predict that consumption growth positively causes output growth. The source of failure is still the crowding-out effect: Demand shocks crowd out consumption at the impact period during which neither output nor investment is able to respond.

There seem to be no simple remedies for the problems identified. More fundamental modifications to existing models are required to fully explain the causal aspects of the business cycle in general equilibrium. One possible remedy is to allow for inventory accumulation, so as to further mitigate the crowding-out effect on consumption. Because general equilibrium business cycle models with inventories are still at an early stage of development, this channel is left as a future research topic. ${ }^{5}$

\section{THE CAUSAL RELATIONSHIPS}

To document the causal relationships among aggregate consumption, output, and investment,

\footnotetext{
4 In the rest of the paper, "cause" and "Granger-cause" are used interchangeably.

5 For the recent development in the inventory literature, see Khan and Thomas (2004) and Wen (2005a).
}

I first estimate the following equations by ordinary least squares ${ }^{6}$ :

$$
\begin{gathered}
\Delta y_{t}=f\left(\Delta y_{t-1}, \Delta y_{t-2}\right), \\
\Delta y_{t}=f\left(\Delta y_{t-1}, \Delta y_{t-2}, \Delta i_{t-1}\right), \\
\Delta y_{t}=f\left(\Delta y_{t-1}, \Delta y_{t-2}, \Delta c_{t-1}\right),
\end{gathered}
$$

where $\Delta y$ is growth in real GDP, $\Delta i$ is growth in business fixed investment, and $\Delta c$ is growth in real consumption of nondurable goods and services. A variable $x$ is said to Granger-cause a variable $y$ when a prediction of $y$ on the basis of its history can be improved by further taking into account the previous period's $x$. Estimating (1), (2), and (3) gives the following results ( $t$-values are in parentheses, the 5 percent significance level [denoted throughout by an asterisk] is \pm 1.96 ):

(4)

$$
\begin{aligned}
\Delta y_{t}= & 0.005+0.29 \Delta y_{t-1}+0.12 \Delta y_{t-2}, \\
& (6.18)^{*} \quad(4.36)^{*}
\end{aligned}
$$

(5)

$$
\begin{aligned}
\Delta y_{t}= & 0.005+0.37 \Delta y_{t-1}+0.16 \Delta y_{t-2}-0.05 \Delta i_{t-1}, \\
& (5.20)^{*} \quad(4.59)^{*} \quad(2.27)^{*} \quad(-1.79)
\end{aligned}
$$

(6)

$$
\begin{aligned}
\Delta y_{t}= & 0.003+0.14 \Delta y_{t-1}+0.12 \Delta y_{t-2}+0.39 \Delta c_{t-1} . \\
& (2.84)^{*}
\end{aligned}
$$

These results lead to the following conclusions: First, based on regressions (4) and (5), I cannot reject the null hypothesis that investment growth in the preceding period has no explanatory power with respect to output growth in the current period, given the history of output growth.

\footnotetext{
The data used are quarterly U.S. data (1947:Q1-2006:Q1). Aggregate output is measured as real GDP minus inventory investment. Inventory investment is excluded from output to highlight the issues addressed in this paper. Namely, if demand shocks are the driving force of the business cycle, inventories would contain the most updated information about consumption movement and may thus mask the causal link from consumption to output. Aggregate consumption is measured as total consumption of nondurable goods and services. Aggregate investment is measured as business fixed investment. All data are taken from the Bureau of Economic Analysis. The growth rate is defined as the first difference in logs. Only two lags are included in the regressions because adding more lags does not change the results significantly. For example, similar results are obtained when four lags are used.
} 
Second, regressions (4) and (6) suggest that past growth in consumption has a significant effect on current output growth even after the history of output growth is taken into account. In fact, consumption growth is such an important factor for determining future output growth that none of the dependent variables in regression (4) remain significant after past consumption growth is taken into account in regression (6). This result suggests consumption growth explains the bulk of future output growth.

For the reversed questions, whether past output growth has an effect on current investment growth given the history of investment growth and whether it also has an effect on current consumption growth given the history of consumption growth, I obtain the following results:

(8)

$$
\begin{aligned}
\Delta i_{t}= & 0.006+0.39 \Delta i_{t-1}+0.04 \Delta i_{t-2}, \\
& (3.64)^{*} \quad(5.99)^{*} \quad(0.54)
\end{aligned}
$$

$$
\begin{aligned}
\Delta i_{t}= & 0.0001+0.18 \Delta i_{t-1}+0.08 \Delta i_{t-2}+0.99 \Delta y_{t-1}, \\
& (0.03) \quad(2.14)^{*} \quad(1.17)
\end{aligned}
$$

$$
\begin{aligned}
\Delta c_{t}= & 0.006+0.21 \Delta c_{t-1}+0.09 \Delta c_{t-2}, \\
& (7.84)^{*} \quad(3.22)^{*}
\end{aligned}
$$

(10)

$$
\begin{aligned}
\Delta c_{t}= & 0.006+0.17 \Delta c_{t-1}+0.08 \Delta c_{t-2}+0.04 \Delta y_{t-1} . \\
& (7.88)^{*} \quad(2.16)^{*}
\end{aligned}
$$

Regressions (7) and (8) suggest that past output growth has a significant effect on current investment growth. On the other hand, regressions (9) and (10) suggest that consumption growth in the preceding period is the best predictor of consumption growth in the current period. Taking into account past output growth does not improve the prediction statistically and economically. This is consistent with Hall's (1978) empirical analysis that the history of consumption is the best predictor of future consumption, except that consumption does not follow a pure random walk.

These results suggest the existence of a oneway "causal" linkage among consumption, output, and investment growth. Namely, consumption growth in the preceding period Granger-causes output growth in the current period; and output growth in the current period in turn Grangercauses investment growth in the next period. To conclude that the causal chains are truly unidirectional, however, I must run two more regressions to eliminate the possibility of feedback from investment growth to consumption growth. I obtain the following results:

(11)

$$
\begin{aligned}
\Delta c_{t}= & 0.006+0.20 \Delta c_{t-1}+0.08 \Delta c_{t-2}+0.01 \Delta i_{t-1}, \\
& (7.84)^{*} \quad(2.89)^{*} \quad(1.16)
\end{aligned}
$$

(12)

Regression (11) suggests that investment growth in the preceding period has no explanatory power for consumption growth in the current period, given the history of consumption growth. This establishes the one-way causal chain. Regression (12) simply confirms that the causal relationships are transitive; namely, if past consumption growth causes current output growth and past output growth causes current investment growth, then past consumption growth must also be significant in predicting current investment growth.

\section{ROBUSTNESS}

The standard Granger causality test gets into trouble when a time series has a moving average component that is not invertible. In that case, finite history of that time series can never be sufficient for predicting its current behavior, rendering other variables significant in improving the prediction. For example, let

$$
\begin{aligned}
& x_{t}=\varepsilon_{t}-\varepsilon_{t-1}, \\
& z_{t}=0.9 z_{t-1}+\varepsilon_{t},
\end{aligned}
$$

where $\varepsilon_{t}$ is an i.i.d. white noise innovation. If one defines the current information set as $\Omega_{t}=\left\{\varepsilon_{t}, \varepsilon_{t-1}, \varepsilon_{t-2}, \ldots\right\}$, then the prediction, $P\left[x_{t} \mid \Omega_{t-1}\right]$, cannot be improved by further taking into account the history of $z_{t},\left\{z_{t-1}, z_{t-2}, \ldots\right\}$. Strictly speaking, therefore, these two series, $x_{t}$ 
and $z_{t}$, do not cause or predict one another. History of $z_{t}$, however, can appear to be significant in predicting the current movement of $x_{t}$ in the linear regression:

$$
x_{t}=\alpha+\sum_{j=1}^{k} \gamma_{j} x_{t-j}+\beta z_{t-1}, \quad 0<k<\infty .
$$

This is so because $z_{t-1}$ contains the entire history of innovations $\left\{\varepsilon_{t-1}, \varepsilon_{t-2}, \ldots\right\}$ useful for predicting $\left\{x_{t-k-1}, x_{t-k-2}, \ldots\right\}$, which are useful for predicting $x_{t}$ when only the finite history, $\left\{x_{t-1}, \ldots, x_{t-k}\right\}$, is included in the information set of the regression.

As a demonstration, a Monte Carlo experiment of the above series gives the following estimation results:

$$
\begin{aligned}
& x_{t}= \\
& 0.0003-0.79 x_{t-1}-0.59 x_{t-2}-0.40 x_{t-3}-0.19 x_{t-4} \\
& \begin{array}{lllll}
(0.03) & (-80.5)^{*} & (-49.0)^{*} & (-33.3)^{*} & (-19.5)^{*}
\end{array} \\
& x_{t}= \\
& -0.0008-0.76 x_{t-1}-0.54 x_{t-2}-0.36 x_{t-3}-0.17 x_{t-4}-0.16 z_{t-1} \text {. } \\
& (-0.07)(-82.0)^{*}(-48.0)^{*}(-31.5)^{*}(-17.8)^{*}(-34.8)^{*}
\end{aligned}
$$

Although $\operatorname{cor}\left(x_{t}, x_{t-j}\right)=0$ for $j \geq 2$, the first regression in (13) shows $x_{t-j}$ are highly significant in predicting $x_{t}$ even for $j>2$. This happens because $x_{t}$ does not have a finite autoregressive representation when its moving average component is not invertible. Failing to take into account the non-invertible moving average component can render other variables such as $z_{t-1}$ significant in predicting $x_{t}$, although the variable $z_{t}$ contains no better information than what is in $x_{t}$ regarding $\varepsilon_{t}$. The second regression in (13) confirms that $z_{t-1}$ is highly significant in predicting $x_{t}$. Even though the history of $x_{t}$ predicts $x_{t}$ reasonably well $\left(R^{2}=0.39\right)$, past $z_{t}$ improve the prediction $\left(R^{2}=0.46\right)$.

A sensible solution for this pitfall is to use a two-stage regression: Fit an optimal $\operatorname{ARMA}(p, q)$ model to a stationary time series, and then regress the estimated residual from the $\operatorname{ARMA}(p, q)$ model against the history of other variables that are of interest. If these other variables appear to be significant in predicting movements in the estimated residual series, then there is said to exist Granger causality between these other variables and the first time series.

If we apply this idea to the above example, regressions based on Monte Carlo simulations give the following results ( $t$-values are in parentheses):

$$
\begin{gathered}
x_{t}=\varepsilon_{t}-0.999 \varepsilon_{t-1}+u_{t} ; \\
(-2146.9)^{*} \\
u_{t}=-0.02-0.006 z_{t-1} ; \\
(0.03) \quad(-0.48) .
\end{gathered}
$$

As expected, the results show that past $z_{t}$ are not significant in predicting current $x_{t}$ after the moving average component of $x_{t}$ is taken into account.

This point is relevant to my analyses of the U.S. data because the first differences of output, consumption, and investment could contain moving average components that are not invertible when the log levels of these variables are not exactly random walk series. In such cases, consumption growth in the previous period can appear to be significant in predicting output growth in the current period even when in fact it does not contain any information superior to that in output. This point is also relevant to my theoretical analysis in what follows because the growth rates of output and other variables in the models have a moving average component.

With this extended notion of Granger causality in mind, I reexamine the identified causal relationship by estimating an $A R M A(4,1)$ model for the growth rate of each of the three macro variables. I find that the moving average coefficients for all three variables are highly significant and are all close to 1 in absolute value. I then use the estimated residuals obtained from each ARMA estimation in a second-stage regression with respect to a constant and the lagged growth rate of another variable. For the case of output growth, I obtain results, as show in Table 1, in the secondstage estimation.

The second-stage regression shows that the estimated residual of output growth obtained from the ARMA model is not exogenous with respect to consumption growth in the preceding period. Namely, consumption growth in the preceding 


\section{Table 1}

\section{Generalized Granger Test for $\Delta y_{t}$}

\begin{tabular}{lcc} 
Independent variable & Coefficient & $\boldsymbol{t}$-Value \\
\hline$\Delta c_{t-1}$ & 0.58 & $3.83^{*}$ \\
$\Delta i_{t-1}$ & 0.03 & 1.08
\end{tabular}

period helps predict current output growth even after the history of output growth and the moving average bias are taken into account. This is consistent with the earlier results obtained above: Consumption growth causes output growth. Similarly, I cannot reject the null hypothesis that investment growth in the preceding period has no explanatory power with respect to output growth in the current period (see the bottom row in Table 1). This is also consistent with the results obtained earlier: Investment growth does not cause output growth.

With respect to consumption growth, I obtain the results shown in Table 2 in the second-stage estimation. It is also consistent with earlier results that neither output growth nor investment growth in the preceding period has explanatory power for consumption growth. The second-stage regression of investment growth gives the results in Table 3.

The table shows that investment growth in the current period is predictable by consumption growth in the preceding period. This is also consistent with the earlier result. Output growth in the preceding period, however, lost its significance in predicting current investment growth at the 5 percent significance level. It is, however, still significant at the 10 percent significance level. In addition, judged by the economic significance, past output growth still helps predict current investment growth very well. The coefficient of $\Delta y_{t-1}$ in the regression is 0.30 with a standard error of 0.18 .

In sum, taking into account the potential bias caused by non-invertible moving average components in the growth rates does not change the conclusions I drew earlier: Postwar U.S. aggregate data exhibit a "causal" chain among consumption, output, and investment. That "causality" runs in

\section{Table 2}

\section{Generalized Granger Test for $\Delta c_{t}$}

\begin{tabular}{lcc} 
Independent variable & Coefficient & $\boldsymbol{t}$-Value \\
\hline$\Delta y_{t-1}$ & 0.001 & 0.04 \\
$\Delta i_{t-1}$ & 0.02 & 1.55
\end{tabular}

\section{Table 3}

\section{Generalized Granger Test for $\Delta i_{t}$}

\begin{tabular}{lcc} 
Independent variable & Coefficient & $\boldsymbol{t}$-Value \\
\hline$\Delta c_{t-1}$ & 0.95 & $2.59^{*}$ \\
$\Delta y_{t-1}$ & 0.30 & 1.61
\end{tabular}

only one direction: from consumption growth to output growth and from output growth to capital formation. Within this causal chain, the impact of consumption growth on both output and investment growth appears to be very powerful and highly robust.

These results reinforce the empirical findings by Hall (1978) and Cochrane (1994). They suggest that there exist certain types of shocks in the U.S. economy that affect consumption before having any impact on output and investment. These shocks cannot be total factor productivity shocks, as output would react immediately to productivity shocks and it is unlikely that consumers are better informed of these shocks than firms. For this reason, in what follows, I try to rationalize the documented empirical regularity by introducing information frictions and demand shocks. However, to be convincing, I first present results obtained in standard models under technology shocks.

\section{PREDICTIONS OF A STANDARD RBC MODEL}

A simple RBC model can be cast in the following form in which a representative agent solves 


\section{Table 4}

\section{RBC Model (t-values in parentheses)}

\begin{tabular}{cccccc}
\multicolumn{2}{c}{ Equation for $\Delta \boldsymbol{y}_{\boldsymbol{t}}$} & \multicolumn{2}{c}{ Equation for $\Delta \boldsymbol{i}_{\boldsymbol{t}}$} & \multicolumn{2}{c}{ Equation for $\Delta \mathbf{c}_{\boldsymbol{t}}$} \\
\hline$\Delta c_{t-1}$ & $0.04(0.73)$ & $\Delta c_{t-1}$ & $0.24(1.13)$ & $\Delta y_{t-1}$ & $0.00(0.09)$ \\
$\Delta i_{t-1}$ & $0.00(0.03)$ & $\Delta y_{t-1}$ & $0.01(0.30)$ & $\Delta i_{t-1}$ & $0.00(0.10)$
\end{tabular}

$$
\max _{\left\{k_{t+j+1}, c_{t+j}, n_{t+j}\right\}} E_{t}\left\{\sum_{j=0}^{\infty} \beta^{j} \log \left(c_{t+j}\right)-a \frac{n_{t+j}^{1+\gamma}}{1+\gamma}\right\}
$$

subject to

$$
c_{t+j}+k_{t+1+j}-(1-\delta) k_{t+j} \leq A_{t+j} k_{t+j}^{\alpha} n_{t+j}^{(1-\alpha)}
$$

and $k_{0}>0$. In equilibrium, consumption, output, and investment in a RBC model should follow these decision rules near the steady state:

$$
\begin{aligned}
& c_{t}=\pi_{c k} k_{t}+\pi_{c A} A_{t}, \\
& y_{t}=\pi_{y k} k_{t}+\pi_{y A} A_{t}, \\
& i_{t}=\pi_{i k} k_{t}+\pi_{i A} A_{t}, \\
& k_{t+1}=\pi_{k k} k_{t}+\pi_{k A} A_{t},
\end{aligned}
$$

where $k$ is the capital stock and $A$ is technology. Utilizing the law of motion for the capital stock, the above equilibrium decision rules can be further expressed as

$$
\begin{aligned}
& C_{t}=\pi_{k k} C_{t-1}+\pi_{c A} A_{t}+\left(\pi_{c k} \pi_{k A}-\pi_{c A} \pi_{k k}\right) A_{t-1}, \\
& y_{t}=\pi_{k k} y_{t-1}+\pi_{y A} A_{t}+\left(\pi_{y k} \pi_{k A}-\pi_{y A} \pi_{k k}\right) A_{t-1}, \\
& i_{t}=\pi_{k k} i_{t-1}+\pi_{i A} A_{t}+\left(\pi_{i k} \pi_{k A}-\pi_{i A} \pi_{k k}\right) A_{t-1} .
\end{aligned}
$$

Clearly, these equilibrium laws of motion imply that consumption, output, and investment all contain the same information about the history of technology shocks, hence neither variable should appear to Granger-cause another variable. For example, once the history of output is taken into account, consumption in the previous period should have no additional explanatory power on current output.

To confirm this, I simulate the model to obtain artificial data series for consumption, output, and investment (sample size $=10,000$ ), under the assumption technology shocks follow the process $A_{t}=\rho A_{t-1}+\varepsilon_{t}$. Because the equilibrium law of motion for $\{c, y, i\}$ suggests that the growth rates of all variables follow an $A R M A(1,1)$ process if $\rho=1$ and an $\operatorname{ARMA}(2,1)$ process if $\rho=0.9$, they all contain moving average components. I therefore apply the two-stage regression procedure discussed in the previous section to estimate causal relationships among the growth rates of the three variables. In the first stage, I apply an $A R M A(2,1)$ model to obtain the residual series. The estimated residuals from the $A R M A(2,1)$ model are then used in the second-stage regression to determine the presence of Granger causality. The results obtained are noted in Table $4 .^{7}$

The table shows that none of the variables Granger-cause each other once its own history is taken into account. The coefficients are all statistically insignificantly different from zero. This is expected because all variables in the model share the same information about technology shocks. Hence, adding other variables to the regressions does not improve the prediction.

\section{PREDICTIONS WITH SEQUENTIAL INFORMATION STRUCTURE}

This section embeds a sequential information structure into the benchmark model so as to create information differentials among output, consumption, and investment. To create an information differential between output and consumption so that consumption contains better information

\footnotetext{
7 The time period is one quarter and the model's parameters are calibrated as follows: the time discounting factor $\beta=0.99$, the capital's share $\alpha=0.3$, the rate of capital depreciation $\delta=0.025$, the inverse labor supply elasticity $\gamma=0$ (Hansen's [1985] indivisible labor), and the persistence parameter $\rho=0.9$. The results are not sensitive to these parameter values.
} 
than output, we need shocks that can affect consumption without affecting output in the initial period. This suggests we need to consider demand shocks instead of technology shocks. ${ }^{8}$ Hence I make the following assumptions: (i) The source of the business cycle is from aggregate demand, and demand shocks can affect consumption instantaneously. (ii) Decisions about employment must be made one period in advance; this implies that output cannot respond to demand shocks immediately, but only with a lag behind consumption. (iii) Investment decisions must be made two periods in advance; this implies that firms' investment cannot respond to demand shocks immediately, but only with a lag behind output.

Under these assumptions, the representative agent's problem is to solve

$$
\max _{\left\{k_{t+1+j}\right\}} E_{t-2}\left\{\max _{\left\{n_{t+j}\right\}} E_{t-1}\left\{\max _{\left\{c_{t+j}\right\}} E_{t}\left\{\sum_{j=0}^{\infty} \beta^{j} \log \left(c_{t+j}\right)-a \frac{n_{t+j}^{1+\gamma}}{1+\gamma}\right\}\right\}\right\}
$$

subject to

$$
c_{t+j}+g_{t+j}+k_{t+1+j}-(1-\delta) k_{t+j} \leq A_{t+j} k_{t+j}^{\alpha} n_{t+j}^{(1-\alpha)},
$$

and $k_{0}>0$. I also assume that government spending follows an $A R(1)$ stochastic process in logs, $\log g_{t}=0.9 \log g_{t-1}+\varepsilon_{t}$, where the innovation $\varepsilon_{t}$ is i.i.d. white noise.

The first-order conditions with respect to choices in time periods $t \geq 0$ are given by

$$
\begin{gathered}
\frac{1}{C_{t}}-\lambda_{t}=0 \\
E_{t-1}\left\{a n_{t}^{\gamma}-(1-\alpha) \lambda_{t} A_{t} k_{t}^{\alpha} n_{t}^{(1-\alpha)-1}\right\}=0 \\
E_{t-2}\left\{\lambda_{t}-\beta \lambda_{t+1}\left[\alpha A_{t} k_{t+1}^{\alpha-1} n_{t+1}^{(1-\alpha)}+1-\delta\right]\right\}=0 \\
c_{t}+g_{t}+k_{t+1}-(1-\delta) k_{t}=A_{t} k_{t}^{\alpha} n_{t}^{(1-\alpha)},
\end{gathered}
$$

where the first equation equates the marginal utility of consumption to its shadow price; the second equation equates the expected marginal cost and benefit of hours based on time $t-1$ information; the third equation equates the expected

8 Technology shocks directly impact output. Hence, output always contains the best information possible under technology shocks, and, consequently, it is impossible for consumption to Grangercause output under technology shocks. cost and benefit of investment based on time $t-2$ information; and the last equation is the periodby-period resource constraint.

In equilibrium, consumption, output, and investment in the model should follow the following rules ${ }^{9}$ :

$$
\begin{gathered}
c_{t}=c\left(k_{t}, A_{t}, A_{t-1}, A_{t-2}, g_{t}, g_{t-1}, g_{t-2}\right) \\
y_{t}=y\left(k_{t}, A_{t}, A_{t-1}, A_{t-2}, g_{t-1}, g_{t-2}\right) \\
i_{t}=i\left(k_{t}, A_{t-2}, g_{t-2}\right) .
\end{gathered}
$$

These equilibrium policy rules imply that consumption in the preceding period $\left(c_{t-1}\right)$ helps predict output in the current period $\left(y_{t}\right)$ even after the history of past output, $\left\{y_{t-1}, y_{t-2}, \ldots\right\}$, is taken into account. This is so because $c_{t-1}$ has information about the demand shock $g_{t-1}$ that is useful for predicting $y_{t}$ but is missing in the history of $y_{t}$. They also imply that output in the preceding period $\left(y_{t-1}\right)$ helps predict investment in the current period $\left(i_{t}\right)$ even after the history of investment, $\left\{i_{t-1}, i_{t-2}, \ldots\right\}$, has been taken into account, because $y_{t-1}$ has information about the demand shock $g_{t-2}$ that is useful for predicting $i_{t}$ but is missing in the history of $i_{t}$. Notice that this information structure cannot be obtained under technology shocks because by definition technology shocks affect output directly before they can affect consumption. Therefore, in the following simulations only government shocks are used.

Using similar estimation procedures above, I obtain the results shown in Table 5 from the second-stage regressions. ${ }^{10}$

The first column of the table shows that consumption growth in the preceding period has significant explanatory power for the residual of output growth in the current period. The middle column of the table shows that output growth (as well as consumption growth) in the preceding period has significant explanatory power for the residual of investment growth in the current period. The last column of the table shows that neither output growth nor investment growth in the preceding period has significant effects on

\footnotetext{
9 See Wen (2005b) for details.

${ }^{10}$ The steady-state government spending-to-output ratio is set at $g / y=0.15$.
} 


\section{Table 5}

\section{RBC Model with Sequential Information}

\begin{tabular}{|c|c|c|}
\hline Equation for $\Delta y_{t}$ & Equation for $\Delta i_{t}$ & Equation for $\Delta c_{t}$ \\
\hline$\Delta c_{t-1}-0.27^{*}(-125.2)$ & $\Delta c_{t-1}-0.15^{*} \quad(-79.0)$ & $\Delta y_{t-1} \quad 0.03 \quad(1.42)$ \\
\hline$\Delta i_{t-1}-0.00 \quad(-0.03)$ & $\Delta y_{t-1}-0.66^{*}(-378.1)$ & $\Delta i_{t-1} \quad 0.07^{*}(2.31)$ \\
\hline
\end{tabular}

the residual of consumption growth in the current period. (Although the coefficient on $\Delta i_{t-1}$ is statistically significant, it is economically insignificant.)

Hence, introducing the sequential information structure and demand shocks brings the standard RBC model into closer conformity with the data's causal structure. However, the model fails on two grounds: (i) The causal relationships among consumption, output, and investment are of the wrong sign-they are all negative in the model. (ii) The order of the relative volatilities of consumption, output, and investment is exactly opposite to that of the data: In the model, consumption is more volatile than output, which in turn is more volatile than investment. Both failures are due to the well-known crowding-out effect of government shocks, which renders consumption and output to be negatively correlated and prevents consumption from smoothing when government expenditure fluctuates. This crowding-out problem cannot be resolved by introducing different forms of demand shocks, such as preference shocks.

\section{PREDICTIONS OF A SCALE- ECONOMY MODEL}

Because allowing for demand shocks in the standard models creates the well-known problem of negative comovement among components of aggregate demand, I introduce further modifications into the model to mitigate the crowdingout problem, following the ideas of Wen (1998) and Benhabib and Wen (2004). In the model, output is produced according to the technology

$$
y_{t}=\left(e_{t} k_{t}\right)^{\alpha(1+\eta)} n_{t}^{(1-\alpha)(1+\eta)},
$$

where $e$ is the rate of capital utilization and $\eta>0$ measures the degree of externalities taken as parametric by representative agents. The rate of capital depreciation is linked to the rate of capital utilization in the preceding period according to

$$
\delta_{t}=\frac{1}{\theta} e_{t-1}^{\theta}(\theta>1),
$$

implying that capital depreciates faster when used more intensively. Thus, the law of motion for capital accumulation is given by

$$
k_{t+1}=i_{t}+\left(1-\frac{1}{\theta} e_{t-1}^{\theta}\right) k_{t} .
$$

Under these assumptions, the representative agent's problem is to solve

$$
\max _{\left\{k_{t+1+j}\right\}} E_{t-2}\left\{\max _{\left\{n_{t+j}, e_{t+j}\right\}} E_{t-1}\left\{\max _{\left\{c_{t+j}\right\}} E_{t}\left\{\sum_{j=0}^{\infty} \beta^{j} \log \left(c_{t+j}\right)-a \frac{n_{t+j}^{1+\gamma}}{1+\gamma}\right\}\right\}\right\}
$$

subject to

$$
\begin{gathered}
c_{t+j}+g_{t+j}+k_{t+1+j}-\left(1-\delta_{t+j}\right) k_{t+j} \leq\left(e_{t+j} k_{t+j}\right)^{\alpha(1+\eta)} n_{t+j}^{(1-\alpha)(1+\eta)}, \\
\delta_{t+j}=\frac{1}{\theta} e_{t+j-1}^{\theta}, \quad \theta>1 ;
\end{gathered}
$$

and $k_{0}>0,1>e_{-1}>0 . .^{11}$

Variable capacity utilization and mild externalities can mitigate the crowding-out effect, as shown by Benhabib and Wen (2004). The scale economy model therefore improves the previous models substantially in explaining the observed Granger causalities. Applying the two-stage estimation procedures to the model gives the results shown in Table $6 .{ }^{12}$

\footnotetext{
${ }^{11}$ See Wen (2005b) for details of how to solve this model.

12 The steady-state rate of capital depreciation is set at $\delta=0.025$, which implies the utilization elasticity of depreciation $\theta=1.4$ Following Wen (1998) and Benhabib and Wen (2004), I chose the externality parameter $\eta=0.15$. The results are not sensitive to these parameter values.
} 


\section{Table 6}

\section{Scale Economy Model with Sequential Information}

\begin{tabular}{ccccccc}
\multicolumn{2}{c}{ Equation for $\Delta \boldsymbol{y}_{\boldsymbol{t}}$} & \multicolumn{2}{c}{ Equation for $\Delta \boldsymbol{i}_{\boldsymbol{t}}$} & \multicolumn{2}{c}{ Equation for $\Delta \mathbf{c}_{\boldsymbol{t}}$} \\
\hline$\Delta \boldsymbol{c}_{t-1}-0.02^{*}$ & $(-2.74)$ & $\Delta c_{t-1}$ & $3.08^{*}$ & $(100.3)$ & $\Delta y_{t-1}$ & 0.01 \\
$\Delta i_{t-1}-0.03^{*}$ & $(-21.1)$ & $\Delta y_{t-1}$ & $1.15^{*}$ & $(35.5)$ & $\Delta i_{t-1}-0.00$ & $(-0.70)$
\end{tabular}

The scale economy model improves the performance of the previous models along several dimensions. First, the middle column of Table 6 shows that both consumption growth and output growth in the scale economy model positively cause investment growth. Secondly, the first column of Table 6 shows that the negative causal relationship found between consumption growth and output growth in the previous models is no longer economically significant in the scale economy model, although it is still non-positive. Another significant improvement of the current model is that the relative volatilities among consumption, output, and investment are restored to the right order; namely, consumption is now the least volatile and investment the most volatile in the scale economy model. This smoothing effect is explained by Wen (1998). Capacity utilization and production externalities help smooth consumption because they render the real wage relatively smooth compared with employment.

What has prevented the model from generating a positive causal relationship between consumption growth and output growth? Figure 1 shows the impulse responses of the model to a positive government shock. On impact, consumption decreases significantly, whereas the other variables remain intact. Although consumption starts to rise above the steady state once employment and output are able to adjust in the following periods, the magnitude is relatively small because of consumption smoothing. Thus, the growth rate of consumption is significantly negatively autocorrelated in artificial time series of consumption generated by government shocks, whereas the growth rates of the other variables are all positively autocorrelated. This negative autocorrelation of consumption growth is caused by the crowding-out effect of government shocks at the impact period, during which output and investment are both fixed. As long as output is not allowed to respond to shocks at the impact period, such a crowding-out effect is unavoidable.

\section{REMARKS}

It is important to reiterate that adding technology shocks into the model does not help resolve the problem, because the causal relationships found in the data are conditional predictions. What matters is the information differential between consumption and output. Technology (or any other) shocks will have no effect on the causal chain unless they can change the information differential. Even though technology shocks can create positive correlation between consumption and output, this has nothing to do with conditional predictions. Just as one time series leading another does not imply it also Granger-causes the other time series, a positive correlation between consumption and output does not imply consumption Granger-causes output. This is why simulations with mixed shocks are not considered. Also, adding other forms of demand shocks (such as taste shocks and sunspots shocks) does not change the fundamental picture because, given our framework, these shocks all have a crowding-out effect either on consumption or on investment at the impact period when output in the resource constraint is not able to react to shocks. In fact, if investment is also fixed in the initial period, then consumption is not going to be responsive at all to preference (or sunspot) shocks on impact; consequently, consumption will fail to Granger-cause output. In this case, the model is able to generate positive correlations between consumption growth and output growth 


\section{Figure 1}

\section{Impulse Responses of the Scale Economy Model to Demand Shocks}
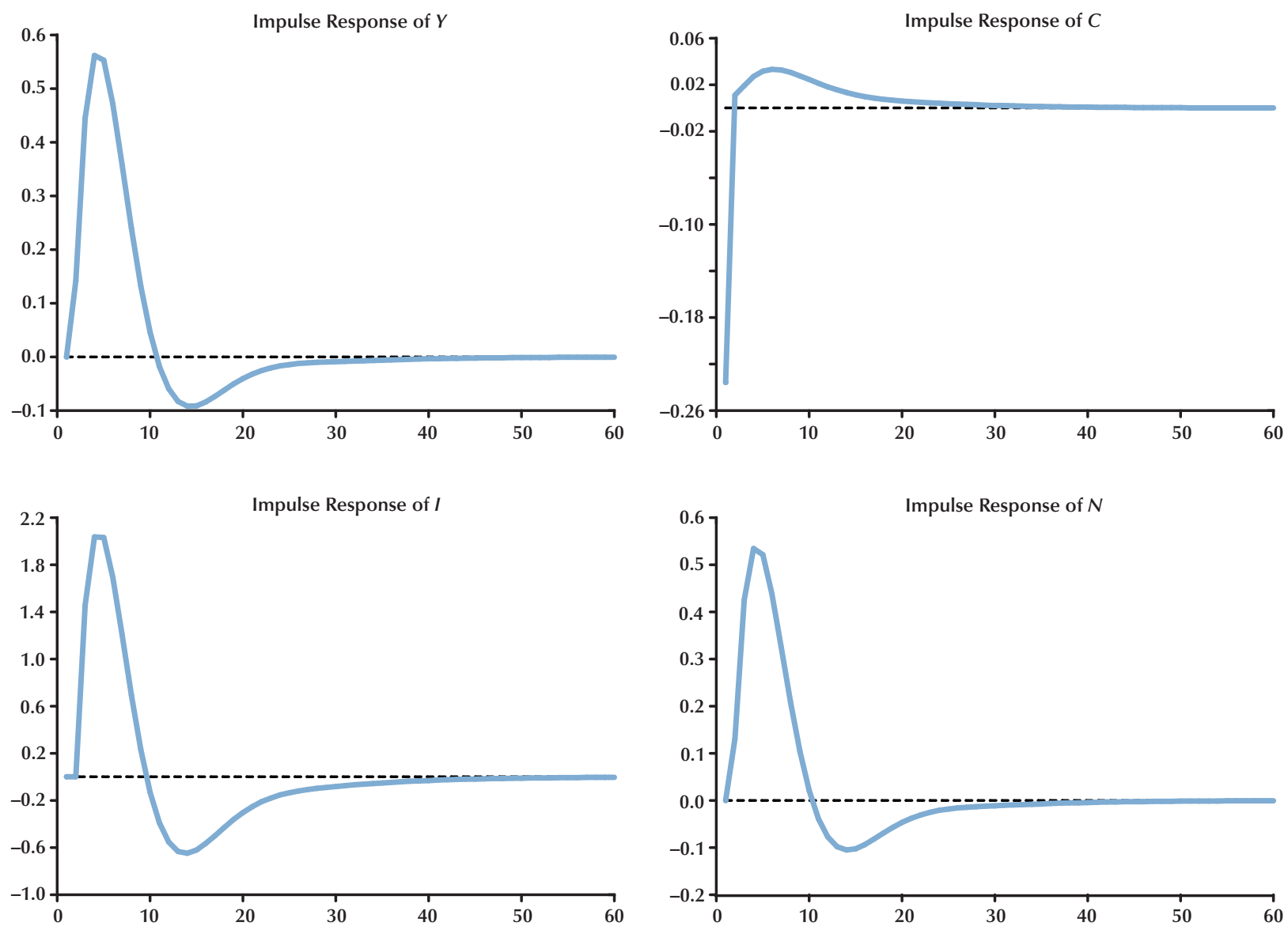

under preference or sunspot shocks, but it still cannot make consumption Granger-cause output. This suggests that the concept of Granger causality adds additional restrictions on economic theory and is thus a powerful litmus test for equilibrium business cycle models.

\section{CONCLUSION}

The U.S. data suggest a "causal” relationship among consumption, output, and investment. This causal relationship may be surprising to some economists, but not to a businessman. According to a businessman's intuition, produc- tion would not rise until consumption demand rises; and investment would not rise until profit rises along with the rise in production. The key elements missing in the businessman's intuition, however, are the aggregate resource constraint and the price mechanism. Without changes in production possibilities or prices, what would enable consumption to rise in the first place without crowding out? General equilibrium business cycle models embodying the resource constraint and price mechanism, nevertheless, have trouble conforming to the data. There must be something fundamental missing in standard models, too. One possible missing element is inventory investment. Inventories provide a perfect buffer for consump- 
tion when output cannot react immediately to demand shocks. To model inventory behavior in general equilibrium, however, is itself a challenge and is therefore beyond the scope of this paper. ${ }^{13}$ My conjecture is that even with inventories introduced, the sequential information structure and the source of shocks (aggregate demand) are still crucial for the model to succeed. Hence, the Granger causality concept and the empirical regularities documented in this paper can prove to be a new litmus test for equilibrium business cycle models.

\section{REFERENCES}

Baxter, Marianne and King, Robert G. "Productive Externalities and Cyclical Volatility." Working Paper No. 245, University of Rochester, 1990.

Benhabib, Jess and Farmer, Roger E.A. "Indeterminacy and Increasing Returns." Journal of Economic Theory, June 1994, 63(1), pp. 19-41.

Benhabib, Jess and Wen, Yi. "Indeterminacy, Aggregate Demand, and the Real Business Cycle." Journal of Monetary Economics, April 2004, 51(3), pp. 503-30.

Burnside, Craig and Eichenbaum, Martin. "FactorHoarding and the Propagation of Business-Cycle Shocks." American Economic Review, December 1996, 86(5), pp. 1154-74.

Cochrane, John H. "Shocks." Carnegie-Rochester Conference Series on Public Policy, December 1994, 41, pp. 295-364.
Granger, Clive W.J. "Investigating Causal Relations by Econometric Models and Cross-Spectral Methods." Econometrica, July 1969, 37(3), pp. 424-38.

Hansen, Gary D. "Indivisible Labor and the Business Cycle." Journal of Monetary Economics, November 1985, 16(3), pp. 309-27.

Hall, Robert. "Stochastic Implications of the Life Cycle-Permanent Income Hypothesis: Theory and Evidence." Journal of Political Economy, December 1978, 86(6), pp. 971-87.

Kahn, Aubhik and Thomas, Julia K. "Modeling Inventories Over the Business Cycle.” Working Paper No. 343, Federal Reserve Bank of Minneapolis, 2004.

Wen, Yi. "Capacity Utilization Under Increasing Returns to Scale." Journal of Economic Theory, July 1998, 81(1), pp. 7-36.

Wen, Yi. "Understanding the Inventory Cycle." Journal of Monetary Economics, November 2005a, 52(8), pp. 1533-55.

Wen, Yi. "Granger Causality and Equilibrium Business Cycle Theory.” Working Paper 2005038A, Federal Reserve Bank of St. Louis, 2005b.

\footnotetext{
${ }^{13}$ For more recent work on this issue, see Kahn and Thomas (2004) and Wen (2005a).
} 
